[3] P. R. Emtage, "Auger recombination and junction resistance in lead-tin telluride," J. Appl. Phys., vol. 47, pp. 2565-2567, 1976.

[4] E. O. Kane, "Band structure of narrow gap semiconductors," in Narrow Gap Semiconductors, Physics and Applications, W. Zawadzki, Ed. Berlin: Springer-Verlag, 1980, pp. 13-31.

[5] A. Haug, "Carrier density dependence of Auger recombination," Solid-State Electron., vol. 21, pp. 1281-1284, 1978.

[6] G. Appold, R. Grisar, G. Bauer, H. Burkhard, R, Ebert; M. Pascher, and H. G. Hafele, "Inter- and intraband magneto-optical trani- tions in $\mathrm{Pb}_{1-x} \mathrm{Sn}_{x} \mathrm{Te}, "$ in Proc, 14th Int. Conf. Phys. Semicond., Edinburgh, Scotland, 1978.

[7] W. W. Anderson, "Gain-frequency-current relation for $\mathrm{Pb}_{1-x} \mathrm{Sn}_{x} \mathrm{Te}$ double heterostructure lasers," IEEE J. Quantum Electron., vol. QE-13, pp. 532-543, 1977.

[8] W. G. Opyd, Document AD 767667, 1973.

[9] O. Ziep, D. Genzow, M. Mocker, and K. H. Herrmann, "Nonradiative and radiative recombination in lead chalcogenides," Phys. Status Solidi (b), vol. 99, pp. 129-138, 1980.

\title{
A Groove GalnAsP Laser on Semi-Insulating InP Using a Laterally Diffused Junction
}

\author{
K. L. YU, U. KOREN, T. R. CHEN, AND A. YARIV
}

\begin{abstract}
Low threshold current GalnAsP/InP groove lasers have been fabricated on semi-insulating InP substrates. Three n-type layers are grown with a single liquid phase epitaxial (LPE) growth process, and the p-n junction is formed by a lateral $\mathrm{Zn}$ diffusion. The active layer inside the groove provides a real index waveguide. Threshold currents as low as $14 \mathrm{~mA}$ with $300 \mu \mathrm{m}$ cavity length are obtained. A single longitudinal mode at $1.3 \mu \mathrm{m}$ up to $1.4 I_{\mathrm{TH}}$ is observed. The lasers operate with a single lateral mode when the active region width is less than $2.5 \mu \mathrm{m}$. This laser is suitable for monolithic integration with other optoelectronic devices.
\end{abstract}

\section{INTRODUCTION}

$\mathrm{T}$ HE integration of semiconductor-based optical and electronic devices has gained considerable interest recently. Most of the demonstrations of such devices, so far, involve the $\mathrm{GaAs} / \mathrm{GaAlAs}$ system. Since GalnAsP/InP lasers are most suitable for fiber communication systems, it is very desirable to develop monolithic integrated optoelectronic circuits in these quaternary systems as well. One of the major problems is the fabrication of a reliable low threshold current laser, especially one suitable for fabrication on semi-insulating (SI) substrates. One possible candidate for this is the transverse junction stripe (TJS) laser which has been fabricated so far in the $\mathrm{GaAs} / \mathrm{GaAlAs}$ system [1]-[3]. In the quaternary system, to our knowledge, no reported structure with a transverse diffused junction has led to lasers with low threshold current. A previously reported TJS structure in a GaInAsP/InP system possesses a very high threshold current [4]. In this letter we report a low threshold current laser, which is fabricated on SI InP substrate, using a laterally diffused junction and a built-in real index waveguide for optical confinement. The resultant structure has the advantage of easy integration with

Manuscript received January 4, 1982. This work was supported by the Office of Naval Research and the National Science Foundation (Optical Communication Program).

The authors are with the California Institute of Technology, Pasadena, CA 91125.

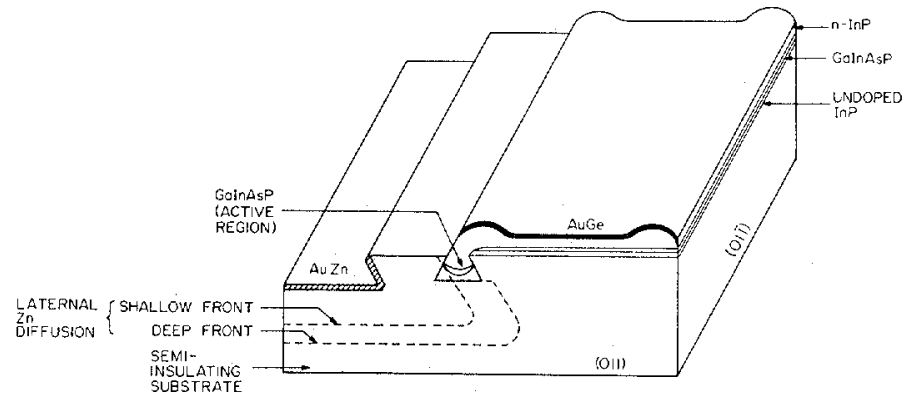

Fig. 1. A schematic cross section of the laser with diffusion touching the active region.

electronic devices, such as metal-insulator-semiconductor fieldeffect transistors.

The laser consists of three epitaxial n-type layers (double heterostructure) grown inside a groove on a semi-insulating substrate, and a lateral $\mathrm{Zn}$ diffused region as shown in Fig. 1 . The current flows laterally from the p-type region across the junction to the n-type region above the groove. As the quaternary layer has a narrower bandgap than the InP, the carrier injection occurs predominantly in the quaternary layer. Current leakage through the InP-InP homojunctions is minimized due to the higher bandgap of the $\mathrm{InP}$. Current leakage through the SI material is very small due to the high specific resistivity of the SI substrate. Optical confinement is obtained by the geometrical structure of the crescent shaped quaternary waveguide. As a result, a low threshold current and a single transverse mode can be obtained.

The preparation of the etched-groove structure on the substrate with $\mathrm{Si}_{3} \mathrm{~N}_{4}$ as an etching mask has been reported recently by us [5]. In the previous structure, we have demonstrated a low threshold current laser with a grown horizontal junction (p-InP, quaternary, and $n$-InP are the LPE grown layers) in a groove on SI InP substrates. In the present structure, starting with the same grooved structure, we use the same growth 
technique with three n-type LPE grown layers and the junction is formed by a lateral diffusion. Thus, similar processing steps are taken in the preparation of the substrates prior to the epitaxy. The fabrication process of this device begins with the chemical vapor deposition (CVD) of $\mathrm{Si}_{3} \mathrm{~N}_{4}$ on the SI InP substrate. Then, grooves are made in the (011) direction of the SI InP substrate through 1.5-5 $\mu \mathrm{m}$ stripe openings. The $\mathrm{Si}_{3} \mathrm{~N}_{4}$ is selectively removed from one side of the groove leaving $100 \mu \mathrm{m} \mathrm{Si}{ }_{3} \mathrm{~N}_{4}$ stripes on the substrate. These stripes act as masks on which no growth occurs during epitaxy. Three LPE layers are grown on the grooved wafer: an undoped InP (background electron concentration is $4-9 \times 10^{16} \mathrm{~cm}^{-3}$ ), a thin (0.1-0.3 $\mu \mathrm{m})$ undoped quaternary GaInAsP layer and an n-type InP $\left(2 \times 10^{18} \mathrm{~cm}^{-3}, \mathrm{Sn}\right.$ doped $)$ layer. The top $\mathrm{n}-\mathrm{In} \mathrm{P}$ is doped higher for low resistance and better electric contact. After the growth, a new $\mathrm{Si}_{3} \mathrm{~N}_{4}$ is deposited and windows for diffusion are opened. The InP underneath these windows is etched down for several microns with 0.5 percent of bromine in methanol solution. $\mathrm{Zn}$ diffusion is then performed at $640^{\circ} \mathrm{C}$ for 20-30 $\mathrm{min}$. The $\mathrm{Zn}$ diffuses laterally for a distance of $4-6 \mu \mathrm{m}$ in the SI InP until it reaches the grooves Fig. 2 shows a photograph of a laser with the $\mathrm{Zn}$ diffusion front touching the active region. After the diffusion, $\mathrm{AuZn} / \mathrm{Au}$ and $\mathrm{AuGe} / \mathrm{Au}$ contacts are evaporated and annealed on the $\mathrm{p}$-side and $\mathrm{n}$-side, respectively. For $\mathrm{CW}$ operation, the lasers are mounted upside up on copper heat sink with conductive epoxy.

Two diffusion fronts are observed in the semi-insulating part of the diffusion path while only one front is observed in the n-layers. As pointed out by Ande et al. [6], for $\mathrm{Zn}$ diffusion, the shallow front corresponds to carrier density of $10^{17}-10^{18}$ $\mathrm{cm}^{-3}$, while the deep front corresponds to carrier density of $10^{15} \mathrm{~cm}^{-3}$ or below. As a result, two fronts are observed in the SI InP which has very low carrier concentration and only one front is observed in the n-layers which are doped above $10^{16} \mathrm{~cm}^{-3}$. Depending on the position of the diffusion front inside the upper $\mathrm{n}^{+}$-InP layer, different laser threshold currents are obtained. For a diffusion front just touching the active region (see Figs. 1 and 2) the lowest threshold current obtained per unit active region width is $5 \mathrm{~mA} / \mu \mathrm{m}$ for lasers with a cavity length of $300 \mu \mathrm{m}$ and an active region thickness of $\sim 0.2 \mu \mathrm{m}$. When the diffusion front is in the middle of the active region inside the groove (see Fig. 3), the lowest threshold current obtained per unit width is $10 \mathrm{~mA} / \mu \mathrm{m}$ for lasers with the same cavity length and active layer thickness. The difference in the threshold current can be explained by the difference in the forward bias current leakage through the InP-InP homojunctions. When the diffusion front just touches the active region, the area of the high doping InP homojunction is minimal. When the diffusion front is in the middle of the active region, a large area $\mathrm{p}-\operatorname{In} \mathrm{P} / \mathrm{n}^{+}-\operatorname{In} \mathrm{P}$ junction above the active region is created (see Fig. 3). The carrier leakage through this $\mathrm{p}-\operatorname{In} \mathrm{P} /$ $\mathrm{n}^{+} \cdot$ InP junction at forward bias results in an increase in the threshold current of the laser.

The light output versus current characteristics of one of the lasers is shown in Fig. 4. The laser threshold current is $17 \mathrm{~mA}$, with a cavity length of $350 \mu \mathrm{m}$. The lowest threshold current

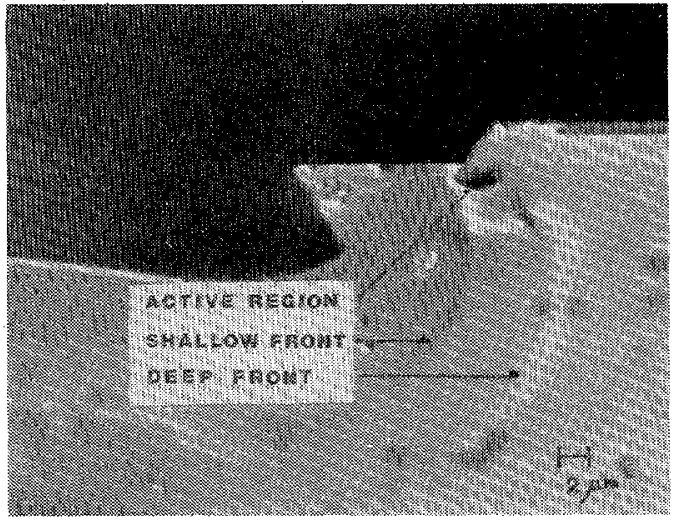

Fig. 2. A photograph of a laser with diffusion performed.

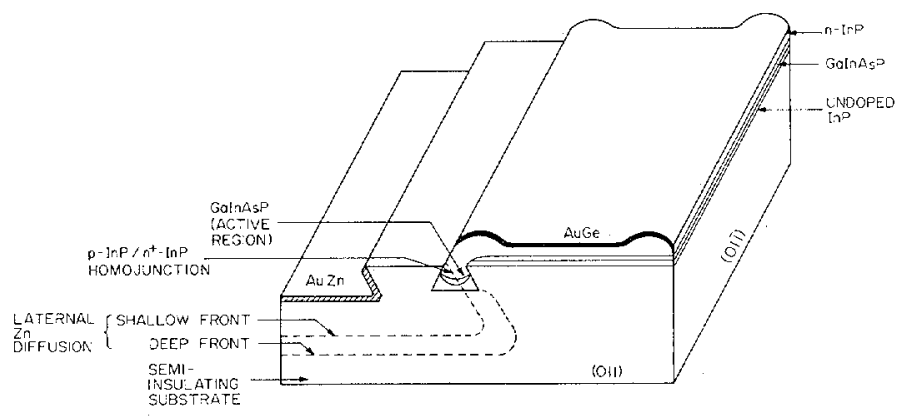

Fig. 3. A schematic cross section of the laser with diffusion in the middle of the active region.

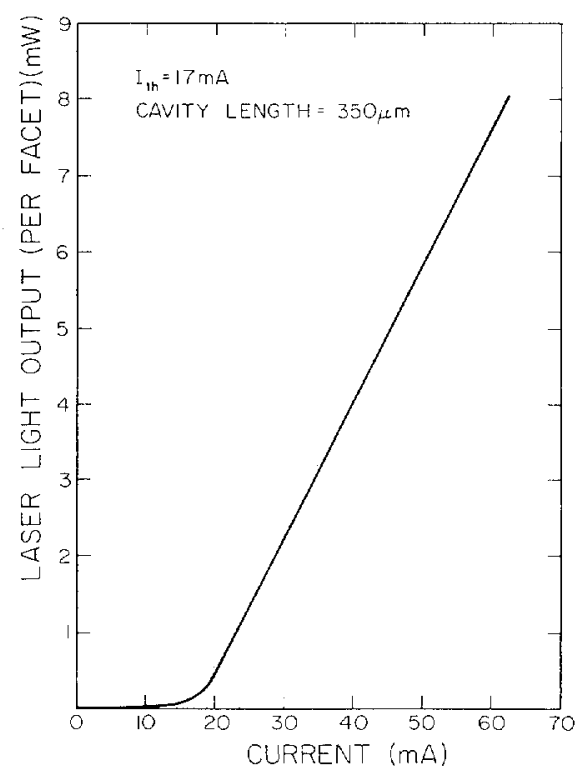

Fig. 4. $L-I$ characteristics of a laser for pulsed operation; $I_{\mathrm{TH}}$ is $17 \mathrm{~mA}$.

obtained is $14 \mathrm{~mA}$ for a laser with a cavity length of $300 \mu \mathrm{m}$. Room temperature $\mathrm{CW}$ operation of the lasers is obtained with threshold current as low as $15 \mathrm{~mA}$. The lasers have a wavelength of $1.3 \mu \mathrm{m}$ and have a single longitudinal mode at up to 1.4 threshold current. The external differential quantum efficiency of these lasers is about 30-40 percent for both facets. A far-field pattern at $\mathrm{CW}$ operation is shown in Fig. 5. A single 


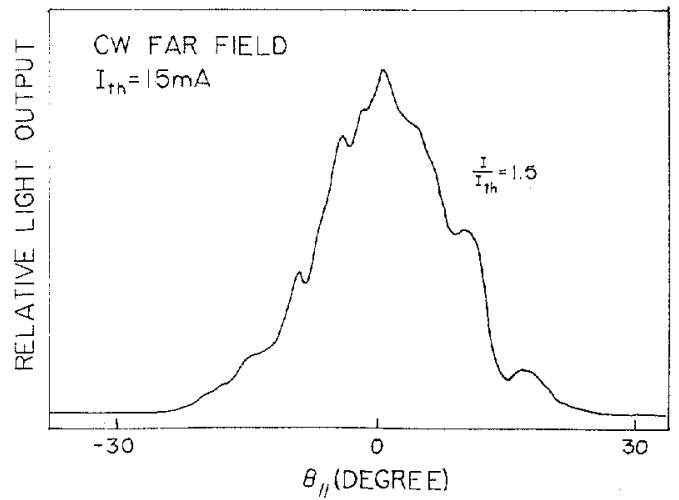

Fig. 5. A far-field pattern at $\mathrm{CW}$ operation of a laser with $I_{\mathrm{TH}}=15 \mathrm{~mA}$.

lateral mode pattern is observed for active region width of less than $2.5 \mu \mathrm{m}$.

\section{CONCLUSION}

In conclusion, we have successfully fabricated a low threshold current laterally diffused junction laser on semi-insulating InP substrate. The optical confinement is provided by the real index waveguide and single-mode $\mathrm{CW}$ operations is obtained.
These properties make this laser a potentially important light source for integrated optoelectronic applications.

\section{ACKNOWLEDGMENT}

The authors would like to thank Dr. N. Bar-Chaim and Dr. S. Margalit of the California Institute of Technology for very helpful discussions.

\section{REFERENCES}

[1] H. Namizaki, H. Kan, M. Ishii, and A. Ito, "Transverse-junctionstripe-geometry double-heterostructure lasers with very low threshold current," J. Appl. Phys., vol. 45, pp. 2785-2786, 1974.

[2] C. P. Lee, S. Margalit, I. Ury, and A. Yariv, "GaAs-GaAlAs injection lasers on semi-insulating substrates using laterally diffused junctions," Appl. Phys. Lett., vol. 32, pp. 410-412, 1978.

[3] C.P. Lee, S. Margalit, and A. Yariv, "GaAs-GaAlAs heterostructure lasers on semi-insulating substrates," IEEE Trans. Electron Devices, vol. ED-25, pp. 1250-1256, 1978.

[4] D. J. Bull, N. B. Patel, F. C. Prince, and Y. Nannichi, "Oxide defined TJS lasers in InGaAsP/InP DH structures," IEEE J. Quantum Electron., vol. QE-15, pp. 710-713, 1979.

[5] K. L. Yu, U. Koren, T. R. Chen, P. C. Chen, and A. Yariv, "Groove GaInAsP laser on semi-insulating InP," Electron. Lett., vol. 17, pp. $790-792,1981$.

[6] H. Ando, N. Susa, and H. Kanbe, "Carrier density profiles in $\mathrm{Zn-}$ and Cd- diffused InP," Japan J. Appl. Phys., vol. 20, pp. L197L200, 1981. 